\section{EFFECTS OF BACKPACK ON GAIT PARAMETERS IN HEALTHY YOUNG INDIVIDUALS USING GAITRITE® SYSTEM \\ Syeda Arooj Kazmi ${ }^{1 \otimes}$, Waqar Afzal', Ashfaq Ahmad', Syed Amir Gilani', Kamran Hanif'}

\begin{abstract}
OBJECTIVE: To find out changes induced in normal gait parameters due to backpack.

METHODS: Thirty university healthy female students participated in this study through convenient sampling technique after taking consent. Participants were asked to walk twice on GAITRite ${ }^{\circledR}$ mat first without carrying backpack and then with a $3 \mathrm{~kg}$ back pack over single shoulder. GAITRite ${ }^{\circledR}$ System version 4.7 .7 was used. The individuals presented with fractures, any type of pain, orthopedic problems, neurological or musculoskeletal disorders, cerebral palsy, myelodysplasia or arthritis and congenital or spinal deformities were excluded.
\end{abstract}

RESULTS: The mean age, height and weight of participants were $21.37 \pm 1.18$ years, 1.62 \pm .043 meters and $45.56 \pm 5.04$ kilogram respectively. Gait was evaluated and there was decrease in the velocity on wearing the backpack on single shoulder in contrast with velocity when no backpack was worn over either left or right shoulder from 109.13 \pm 10.89 to $105.79 \pm 10.85(p=0.001)$, stance parameter of gait had no significant difference when subjects worn the backpack over one shoulder in comparison when walked without carrying the backpack $61.5 \pm 1.42$ to $61.36 \pm 1.53(p=0.288)$. No significant changes were recorded in left double limb support and right double limb support, before and after wearing backpack $23.09 \pm 2.5$ to $22.91 \pm 2.79(\mathrm{p}=0.489)$ and $22.98 \pm 2.42$ to $22.69 \pm 2.78(p=0.348)$ respectively. Same is the case in left single limb support and right single limb support $38.34 \pm 1.37$ to $38.44 \pm 1.53(p=0.565)$ and $38.68 \pm 1.59$ to $38.83 \pm 1.53(p=0.493)$.

CONCLUSION: The study concluded that wearing backpack over one shoulder causes significant changes in velocity while no changes observed in single and double limb support.

KEY WORDS: Gait (MeSH); GAITRite ${ }^{\circledR}$ system (Non-MeSH); Backpack (Non-MeSH); Velocity (Non-MeSH); Single limb support (Non-MeSH); Double limb support (Non-MeSH).

THIS ARTICLE MAY BE CITED AS: Kazmi SA, Afzal W, Ahmad A, Gilani SA, Hanif $K$. Effects of backpack on gait parameters in healthy young individuals using GAITRite ${ }^{\circledR}$ system. Khyber Med Univ J 2018;10(4):21 7-20.

\section{INTRODUCTION}

ndividuals utilize backpacks every day, commonly hang on their shoulders to leave the upper limbs free for different tasks and to make it more easy while walking with load. ${ }^{1,2}$ It is accounted that load of backpacks increase as children are promoted to higher classes. ${ }^{3}$ Excessively loaded backpack and lacking appropriate lifting technique may distribute the weight improperly over human body causing muscle pain, weakness and pressure in various body parts, which may lead to inappropriate stance and spinal deformity. ${ }^{4}$ However human walk is a biomechanical phenomenon which occurs through a series of balanced muscular and inertial forces which yields in the smooth movement of the body. The human musculoskeletal framework and human walking has been thoroughly analyzed. ${ }^{6}$ Essential requirements for walk investigation are the appraisal of spatial temporal step parameters and the examination of developments inside
I University Institute of Physiotherapy, University of Lahore, Lahore, Pakistan Email冈:aroojkazmi4@icloud.com

Contact \# : +92-3217704221

Date Submitted: March 08, 2018

Date Revised: December 04, 2018

Date Accepted: December 06, 2018

consequent walk cycles. This parameterization of gait requires the findings of resulting foot contacts. ${ }^{7}$ Temporal and spatial gait parameters are important to find out the abnormal changes and to diagnose the pathological gait. ${ }^{8}$

From a biomechanical viewpoint, asymmetrical posture while wearing a backpack induces changes in walking pattern. In any case, as individuals constantly carry backpack, they have a tendency to disregard possible issues and unfavorable impacts that may possibly be related with backpacks weight and position of placement. A few investigations have detailed adjustment in the kinematic and dynamic parts of step related with use of backpacks, as confirmed by the progressions in spatiotemporal parameters. Those changes include reduction in velocity, cadence, step length, single support, while increases in double limb support time and stride duration.' However, there are plentiful researches on the impact of backpack on the spatiotemporal gait parameters among young adults. ${ }^{4}$ A few investigations have been centered on walk adaptation to the outside load in such biomechanical conditions as conveying an extra weight. These investigations likewise reported changes in the fundamental spatiotemporal walk measures because of moment over-burden of engine framework. A study demonstrated that the backpack containing heap of $40 \%$ of body weight fundamentally influenced treadmill velocity in youthful sound subjects communicated as the diminishing of walk length with attending increment of walk. ${ }^{4,10}$ Among the population who wear the backpacks youth make the noteworthy percentage of it. ${ }^{4}$ However, the recommendations of safe weight of backpack which should be carried are limited to school age children." Therefore, we presume that evaluating the impact of carrying a backpack on young grown-ups, changeability of gait 
TABLE I: DESCRIPTIVE STATISTICS FOR AGE, HEIGHT AND WEIGHT OF THE STUDY SUBJECTS

\begin{tabular}{|l|c|c|c|}
\hline Descriptive statistics & Age & Height & Weight \\
\hline Mean & 21.37 & 1.62 & 45.56 \\
\hline Std. Error of Mean & 0.34 & 0.00 & 0.92 \\
\hline Std. Deviation & 1.88 & 0.04 & 5.04 \\
\hline Minimum & 18 & 1.55 & 38.00 \\
\hline Maximum & 24 & 1.75 & 60.00 \\
\hline
\end{tabular}

patterns may provide deeper understanding of how physical loads cause changes in gait features under usual situations. In this manner, we expect that surveying the impact of conveying a backpack on youthful grown-ups' fluctuation of step examples may give further comprehension of how physical burdens influence stride attributes under routinely circumstances. ${ }^{4}$ The elementary gait parameters most regularly used are velocity, step length and step frequency. ${ }^{12,13}$

This study will enlighten the effects of backpack use on different gait parameters among university female students vide GAITRite ${ }^{\circledR}$ System version 4.7.7, the main objective of the study is find out changes induced in normal gait parameters due to backpack.

\section{METHODS}

The data was collected from 30 healthy university going females. The participants were enrolled in this study after taking their consent. The formula for sample calculations used in this study

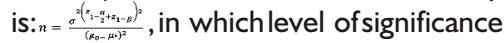
is $5 \%$, power of the test is $90 \%$, population standard deviation is 5.20 , population variance is 27.04 , test value of the population mean is 109.13 and anticipated population mean is 105.79 resulted in sample size of 26 and in this study round of figure 30 has been taken. The system which was used to record the parameters of gait was the GAITRite ${ }^{\circledR}$ System version 4.7.7. Healthy females were included in this study. The individuals having history of fractures, any type pain, orthopedic problems, neurological or musculoskeletal disorders, cerebral palsy, myelodysplasia or arthritis and congenital or spinal deformities were excluded. To rule out postural deformities, observation of posture with naked eye was performed on subjects. The study was carried out in the Biomechanics Laboratory of Department of Physiotherapy at University of Lahore and duration of study was 3 months.

Each subject was well instructed about the procedure before walking on the mat of GAITRite ${ }^{\circledR}$ system. For the first walk subjects were asked to walk on mat of GAITRite ${ }^{\circledR}$ system without any load. In the second walk the subjects were asked to carry a backpack of $3 \mathrm{~kg}$ on one selfselected shoulder to pursue the natural gait and walk on mat of GAITRite ${ }^{\circledR}$ system. Each subject was asked to walk a distance of 2 meters from the mat. Subjects were asked to maintain their normal pattern of gait during walk with or without load. The studied parameters are velocity, stance, single limb support and double limb support while paired sample t-test was applied to analyze the results of this study.

\section{RESULTS}

Thirty female students participated with mean age of $21.37 \pm 1.88$, mean height of $1.62 \pm 0.04$ and mean weight of $45.56 \pm 5.04$ as shown in Table $\mathrm{l}$.

Gait was evaluated as per method mentioned above and there was decrease in the velocity on wearing the backpack on single shoulder, contrasted with velocity when no backpack was worn over either left or right shoulder from $109.13 \pm 10.89$ to $105.79 \pm 10.85$ $(p=0.00 \mathrm{I})$, stance parameter of gait had no significant difference when subjects

TABLE II: PAIRED SAMPLE STATISTICS OF GAIT PARAMETERS OF STUDY SUBJECTS ON GAITRITE® SYSTEM WITH AND WITHOUT WEIGHT CARRIAGE

\begin{tabular}{|c|c|c|c|c|}
\hline Variables & $\begin{array}{c}\text { Descriptive } \\
\text { Statistics } \\
\end{array}$ & $\begin{array}{c}\text { Without Weight } \\
\text { Carriage }\end{array}$ & $\begin{array}{l}\text { With Weight } \\
\text { Carriage }\end{array}$ & $P$ value \\
\hline \multirow{3}{*}{ Velocity $\left(\mathrm{cm} / \mathrm{s}^{2}\right)$} & Mean & 109.13 & 105.79 & \multirow{3}{*}{0.001} \\
\hline & Std. Deviation & 10.89 & 10.85 & \\
\hline & Std. Error Mean & 1.98 & 1.98 & \\
\hline \multirow{3}{*}{ Stance percentage gait cycle } & Mean & 61.5 & 61.36 & \multirow{3}{*}{0.288} \\
\hline & Std. Deviation & 1.42 & 1.53 & \\
\hline & Std. Error Mean & 0.18 & 0.19 & \\
\hline \multirow{3}{*}{ Double limb support (Left) percentage gait cycle } & Mean & 23.09 & 22.91 & \multirow{3}{*}{0.489} \\
\hline & Std. Deviation & 2.5 & 2.79 & \\
\hline & Std. Error Mean & 0.45 & 0.5 & \\
\hline \multirow{3}{*}{$\begin{array}{l}\text { Double limb support (Right) percentage gait } \\
\text { cycle }\end{array}$} & Mean & 22.98 & 22.69 & \multirow{3}{*}{0.348} \\
\hline & Std. Deviation & 2.42 & 2.78 & \\
\hline & Std. Error Mean & 0.44 & 0.5 & \\
\hline \multirow{3}{*}{ Single limb support (Left) percentage gait cycle } & Mean & 38.34 & 38.44 & \multirow{3}{*}{0.565} \\
\hline & Std. Deviation & $\mathrm{I} .37$ & 1.53 & \\
\hline & Std. Error Mean & 0.25 & 0.28 & \\
\hline \multirow{3}{*}{ Single limb support (Right) percentage gait cycle } & Mean & 38.68 & 38.83 & \multirow{3}{*}{0.493} \\
\hline & Std. Deviation & 1.59 & 1.53 & \\
\hline & Std. Error Mean & 0.29 & 0.28 & \\
\hline
\end{tabular}


worn the backpack over I shoulder in comparison when walked without carrying the backpack $(p=0.288)$. No significant changes were recorded in left double limb support and right double limb support, before and after wearing backpack with $p$ values of 0.489 and 0.348 respectively same is the case in left single limb support and right single limb support with $p$ values of 0.565 and 0.493 respectively which were insignificant too (Table II).

\section{DISCUSSION}

The main study aim was to find out the variability in gait parameters when wearing load over one shoulder. The main focus of this study was on velocity, single limb support, double limb support and stance. There were no significant changes in most of the parameters except velocity which is of prime importance and significant change was recorded. This study analyzed changes in parameters under condition of wearing backpack over single shoulder (self-selected) and the result of velocity supported Connolly $\mathrm{BH}$, et al. ${ }^{15}$ study which shows decrease in velocity under load wearing conditions over one shoulder and the same study showed results of increased velocity under loading of two shoulders. The walking speed was maintained constant for all conditions in a study conducted by Kinoshita, et al. ${ }^{14}$

The results of double limb support were conflicted to study by Connolly $\mathrm{BH}$, et al. $^{15}$ and Chow DH, et al. ${ }^{16}$, they reported that weighted backpacks resulted in double support time increase significantly. However, Smith $\mathrm{KU}$, et al. ${ }^{17}$ in study concerning the temporal parameters of gait for single and double support periods showed no significant differences with an increase in load. The study conducted by Chow $\mathrm{DH}$, et al. ${ }^{16}$ reported results of decrease in velocity with single support time. Significant increase in the double support time were seen with increasing backpack load conflicting with our findings with no significant changes in single support and double support time but supported the results of decreased velocity. In this study the weight of backpack was kept constant as it was the average weight of the backpack which the subjects used to carry in their daily life routine. Cottalorda J, et al. ${ }^{18}$ reported that on carrying a backpack (one or two shoulders) the subjects walked with increased stance and with double stance than when walking without a backpack. The outcomes of velocity were consisted with the study of Singh T, et al. ${ }^{10}$ who provided reduced mean velocity for loaded conditions.

\section{CONCLUSION}

This study concluded that wearing load over one shoulder caused significant change in velocity. The other parameters stance, double limb support and single limb support showed no significant change.

\section{LIMITATIONS}

- This research is done only on young population.

- Results were not analyzed on the basis of which single shoulder right or left subject used to wear the backpack. It was self-selected to pursue the natural gait of the subjects.

- Self-selected shoes were worn by the participants.

\section{REFERENCES}

I. Abaraogu UO, Ugwa WO, Onwuka $E$, Orji E. Effect of single and double backpack strap loading on gait and perceived exertion of young adults. J Back Musculoskelet Rehabil 20।6;29(I): I09-I 5.DOI: I0.3233/BMR-I50605.

2. Heuscher Z, Gilkey DP, Peel JL, Kennedy CA. The association of self-reported backpack use and backpack weight with low back pain among college students. J Manipulative Physiol Ther 20।0;33(6):432-7. DOI: 10.1016/j.jmpt.2010.06.003.

3. Forjuoh S, Schuchmann J, Lane B. Correlates of heavy backpack use by elementary school children. Public Health 2004;II8(7):532. DOI: 10.1016/j.puhe.2003.10.010.

4. Lehnen GC, Magnani RM, Sá e Souza GS, Rodrigues FB, Andrade AO, Vieira MF. Effects of backpack loads and positions on the variability of gait spatiotemporal parameters in young adults. Res Biomed Eng 20I 7;33(4):277-84. DOI: 10.1590/2446-4740.03517.

5. Błaszczyk JW, Plewa M, CieœlinskaSwider J, Bacik B, ZahorskaMarkiewicz B, Markiewicz A. Impact of excess body weight on walking at the preferred speed. Acta Neurobiol Exp (Wars) 20I I;7I (4):528-40.

6. Lovejoy CO. The natural history of human gait and posture: Part I. Spine and pelvis. Gait Posture 2005;2I(I):95-II2. DOI: 10.1016/j.gaitpost.2004.01.001.

7. Zijlstra W, Hof AL. Assessment of spatio-temporal gait parameters from trunk accelerations during human walking. Gait Posture 2003 ; I 8(2): I - I0. DOI: 10.1016/S0966-6362(02)00190-X.

8. Hebenstreit F, Leibold A, Krinner S, Welsch G, Lochmann M, Eskofier BM. Effect of walking speed on gait sub phase durations. Hum Mov Sci $20 । 5 ; 43$ : I I $8-24$. DOI: 10.1016/j.humov.20I5.07.009.

9. Birrell SA, Haslam RA. The effect of military load carriage on 3-D lower limb kinematics and spatiotemporal parameters. Ergonomics 2009;52(I0): I298-304. DOI: 10.1080/00|40|30903003II5.

10. Singh T, Koh M. Effects of backpack load position on spatiotemporal parameters and trunk forward lean. Gait Posture 2009;29( I):49-53. DOI: 10.1016/j.gaitpost.2008.06.006.

I I. Rai A, Agarwal S, Bharti S. Postural effect of back packs on school children: its consequences on their body posture. Int J Health Sci Res 2013;3(10): 109-16.

12. Oberg T, Karsznia A, Oberg K. Basic gait parameters: reference data for normal subjects, 10-79 years of age. J Rehabil Res Dev 1993;30(2):2 10-23.

13. Finley FR, Cody KA, Finizie RV. Locomotion patterns in elderly women. Arch Phys Med Rehabil 1969;50(3): 140-6.

14. Kinoshita $H$. Effects of different loads and carrying systems on 
selected biomechanical parameters describing walking gait. Ergonomics I $985 ; 28(9): 1347-62$. DOI: |0.1080/00|40|3850896325।.

15. Connolly BH, Cook B, Hunter S, Laughter M, Mills A, Nordtvedt N, et al. Effects of backpack carriage on gait parameters in children. Pediatr Phys Ther 2008;20(4):347-55. DOI:
I0.1097/PEP.0b0I 3e3I8I8a0f8f.

16. Chow DH, Kwok ML, Au-Yang AC, Holmes AD, Cheng JC, Yao FY, et al. The effect of backpack load on the gait of normal adolescent girls. Ergonomics 2005;48(6):642-56. DOI: $10.1080 / 00140130500070921$.

I7.Smith KU, McDermid CD,
Shideman FE. Analysis of the temporal components of motion in human gait. Am J Phys Med 1960;39(4):|42-5I.

18. Cottalorda J, Rahmani A, Diop M, Gautheron V, Ebermeyer E, Belli A. Influence of school bag carrying on gait kinetics. J Pediatr Orthop B 2003; 12(6):357-64.

\section{AUTHORS' CONTRIBUTIONS}

Following authors have made substantial contributions to the manuscript as under:

SAK: Acquisition of data, drafting the manuscript, final approval of the version to be published.

WA: Concept \& study design, acquisition, analysis \& interpretation of data, drafting the manuscript, final approval of the version to be published.

AA \& SAG: Critical review, final approval of the version to be published.

$\mathbf{K H}$ : Analysis \& interpretation of data, final approval of the version to be published.

Authors agree to be accountable for all aspects of the work in ensuring that questions related to the accuracy or integrity of any part of the work are appropriately investigated and resolved. 